\title{
WSN-Based Information Dissemination for Optimizing Irrigation Through Prescriptive Farming
}

Balakrishna K., Maharaja Institute of Technology, India

\begin{abstract}
Prescriptive agriculture is the art of science utilizing modern technology to enhance productivity with optimizing inputs/cost. In this paper, the advent of wireless sensor network, APSim, and statistical software spurred a new direction in the farming domain at optimizing irrigation. Sensors are designed to collect the datasets of climatic parameters such as relative humidity and temperature, where the datasets were forwarded to the server through a GSM module. Datasets collected were analyzed through statistical software for grown crops by considering field soil conditions and evapotranspiration. Finally, information on irrigation is determined through an algorithm designed by way2SMS and WebHost server.
\end{abstract}

\section{KEYWORDS}

APSim, Prescriptive Agriculture, Wireless Sensor Network (WSN)

\section{INTRODUCTION}

Present-day farming insists on raising productivity per unit of land to fulfill food demand for a large population with reduced farming land area. Towards achieving this goal, farmers go with conventional wisdom solutions like drip irrigation, adequate use of fertilization, crop pattern, etc. During the growth stages of a plant depends on various factors like environmental conditions, soil, and climate to produce good yield during harvesting. In farming, water plays an important factor in the absorption of nutrients and photosynthesis through plant tissue cells (Jensen, M.E., Allen, R.G., 2016). Where plants get water through naturally like raining, moisture content in air and soil, water applying externally to supplement the requirement is called irrigation. The adequate application of irrigation helps in the performance of crops not only directly but also indirectly by influencing the availability of other nutrients, the timing of the cultural operation, etc. Irrigation in India includes network of major and minor canals, rainfall, groundwater and tanks, where currently in India around $51 \%$ of land is covered by irrigation land and rest of the land depends on rainfall. In this regard, the utilization of water for agriculture should be optimized by the usage of technologies.

WSN (Wireless Sensor Network) refers to a spatially distributed wireless network devices that use the sensor to monitor the physical environment parameters in real-time. New technology and solutions are being applied in this domain to provide an optimal alternative to gather and process information to optimize irrigation through statistical software (Ning Jin et al., 2010). Moreover, alarming climate change and scarcity of water demand new and improved methods for modern farming. Precision Agriculture is on the most promising domain in observing, measuring and responding to inter and intra field variability through WSN. A key component of the precision agriculture approach is the 
use of information technology through a wide array of components such as sensors, GSM module, automated hardware, and software. Enforcement of precision agriculture decisions in real-time leads to a new domain called prescriptive agriculture.

Prescriptive Agriculture is the next level of technology evolution after the precision agriculture in benchmarking the farm profitability, nutrient and water application to plant and productivity to keep the farm sustainable. It is a detailed, site-specific recommendation and insight to help farmers maximize their produce with minimizing inputs. There is a large volume of data that will be captured by technology and sort this data into required and can be utilized by the farmers to help make more detailed decisions on crop management. APSim software is statistical software, here using to analyze the data and in decision making for irrigation (Balakrishna K., \& Rao, M., 2019). In this paper, a new approach is proposed for optimization of irrigation for horticulture crops based on WSN, statistical software and modern technology.

\section{LITERATURE SURVEY}

(T. Ojha, S. Misra and N.S. Raghuwanshi, 2015) reviewed the potential of future challenges associated with deploying WSN and its applicability in agriculture and farming towards improved performance and productivity along with specific issues associated with it. Paper considers two main variants of WSN i.e. Terrestrial Wireless Sensor Network (TWSN) and Underground Wireless Sensor Network (UWSN), a TWSN is a node above the ground surface and UWSN is a node planted inside the soil to determine the moisture content of the soil and decide the irrigation schedule. Comparatively, TWSN suits better than UWSN for selected features condition, where the gateway node is used to collect the information. Then the information can be transmitted over the Wi-Fi, GPRS or Bluetooth to reach a remote database and finally to the user through a cell phone.

(Tuan Dinh Le and Dat Ho Tan., 2015) designed WSN to collect environmental parameters such as Temperature and Humidity at an interval of 30 minutes for nearly 6 months i.e 48 datasets per day. On the software part, he proposed the Management framework for Precision Agriculture as a data collection module, the controller module, and the data prediction module. Decision making and action performing policy are taken care of by the controller module and Prediction done based on the stochastic process of Dynamic Bayesian Network for predicting parameters. Based on the performance evaluation of the proposed prediction module for temperature and humidity is $77.5 \%$ and $67.6 \%$ respectively.

(S. R. Nandurkar, V. R. Thool and R. C. Thool, 2014) designed a WSN to collect environmental parameters such as Temperature and Humidity regularly. The centralized control unit regulates the flow of water in real-time based on the closed-loop feedback system on the instantaneous temperature and humidity values. (Srbinovska, M et al., 2015) proposed WSN architecture for greenhouse pepper vegetables for achieving lower management cost and scientific cultivation to improve quality in agriculture production from the environmental prospects. The environmental parameters such as Temperature, Humidity, and Illumination are collected using WSN technology. Based on the collected datasets appropriate tasks such as irrigating and fan facilities, to control the temperature in the greenhouse, would be activated.

(Anisi, M.H., Abdul-Salaam, G. \& Abdullah, A.H., 2015) reviewed energy consumption during data acquisition, transmission, and processing for the WSN system in monitoring environmental parameters. First, the various topologies of WSN including Star single-hop, Cluster tree-based multihop and mesh network are studied with considering power sources as battery and solar. Second, in Precision Agriculture the current WSN approaches used are reviewed and categorized based on the power source. Finally, based on the application, parameters and technical contributions are reviewed.

(F. B. Culibrina and E. P. Dadios, 2015) collected the soil moisture, temperature, and humidity by installing sensors on the vegetable crop. The wireless data transmission is done using the ZigBee protocol due to its low power consumption for long battery life and manipulates power distribution in 
transreceiving dataset. (A. L. Diedrichs et al., 2014) also worked on minimizing the power consumption of the power network in measuring temperature for Precision Agriculture. For communication interface, developed a serial protocol i.e. SDI-12 for gathering the data. Here the RFD (Reduced Function Device) is designed to wake for every clock tick, if there is nothing to do, again return to sleep mode for long time battery usage.

(M. R. Mohd Kassim, I. Mat and A. N. Harun, 2014) worked on solving the agriculture problems using WSN through real-time field monitoring by optimizing, decision making and support with collected datasets. Using the principles of the Internet of Things (IoT) designed software control, hardware and network architecture of the Precision Irrigation system. The experiment is conducted for 1000 capsicum annum plants in the Greenhouse management system based on scheduled and automated irrigation methods by measuring parameters such as soil moisture, temperature, and humidity. Their result showed that automatic irrigation is efficient compared to the scheduled irrigation system.

(Navarro-Hellín, H et al., 2015) proposed an Automatic SIDSS (Smart Irrigation Decision Support System) based on two machine learning techniques PLSR (Partial Least Square Regression) and ANFIS (Adaptive Neuro-Fuzzy Interference Systems). The researchers used a 15 minutes interval irrigation schedule based on soil and climatic conditions. The experiment was conducted for lemon trees in South-East Spain considering three commercial plantations. The performance of the system is analyzed by comparing it with the decision support component of PLSR and ANFIS.

(Navarro-Hellín, H et al., 2016) proposed WSN architecture with GPRS connectivity to collect information on environmental parameters. The server stores the information sent from the remote place in a database, thus allowing the users to consult and analyze the information obtained to optimize the water management resource. For better performance tests, the sampling rate is adjusted to 15 minutes and sending rate to 30 minutes. Several papers articulate various works on a decision support system to meet the sufficient demand for water resource management in the agriculture field (Rinaldi, M., He, Z., 2014, N. Kaewmard and S. Saiyod, 2014, S. Khriji et al., 2014, Chartzoulakis, K., Bertaki, M., 2015, I. Mat, M. R. M. Kassim and A. N. Harun, 2014 and R. K. Kodali, N. Rawat and L. Boppana, 2014). Sensors are used to monitor temperature, humidity and soil moisture in the field and forwarded it to the remote places for further actions to be taken as described in these papers. They also provide the necessary logic to help in overcoming the wrong prediction of weather and inappropriate irrigation method for selected crops.

State-of-the-art from the above methods and models suggest that optimization of irrigation is still infancy. Prescriptive Agriculture technology is an emerging area advancing the adaptation of precision agriculture, which seems to have a lot of opportunities for researchers.

\section{3.. PROPOSED METHODOLOGY}

In the proposed method, the system works in three stages. At the initial stage, WSN records and forwards the temperature and relative humidity datasets through a GSM (Global System for Mobile Communication) module. After receiving the datasets, based on the crop and their growth stages decision will be taken by the statistical software for further processing. Finally, the optimization of irrigation for the crops at real-time climatic conditions based on the volumetric water analysis model through APSim. The information on irrigation time is decimated to farmers through a communication model as shown in Figure 1. Here the acquired datasets through sensors are transmitted wirelessly using a GSM technology to the individual farmers mobile.

\subsection{GSM Module}

GSM system is a combination of FDMA (Frequency Division Multiple Access), TDMA (Time Division Multiple Access) and Frequency hopping with a frequency band of 890 to $915 \mathrm{MHz}$ (uplink) and 935 to $960 \mathrm{MHz}$ (downlink). Uplink is the link between from ground station to satellite 
Figure 1. Conceptual diagram explaining the notion of sensing farm field climate for optimizing irrigation based on the model and to give Decision action

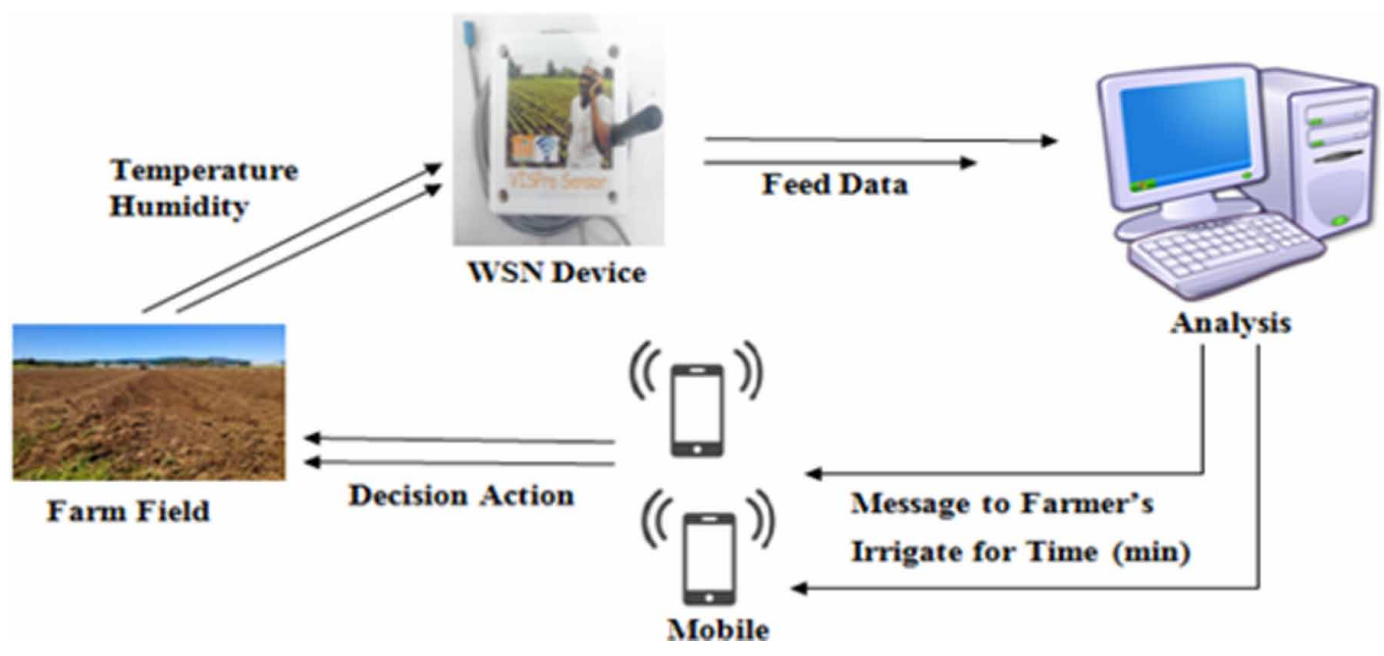

and downlink is the link between from satellite to ground station. To avoid the interference between the guard bands, three main control channels are used $\mathrm{BCH}$ (Broadcast Channel), $\mathrm{CCCH}$ (Common Control Channel) and DCCH (Dedicated Control Channel).

\subsection{WSN Based Dataset Collection}

An integrated low power WSN designed to collect temperature and humidity from the farm field. The design of WSN is as shown n Figure 2, where the DHT11 sensor measures the temperature and humidity of the field (micropik, 2010). Temperature is measured from the semiconductive material for small changes in temperature leads to the large changes in resistance based on the negative temperature coefficient. Humidity is measured using two electrodes with moisture holding substrate between them, while the resistance or conductivity changes lead to changes in humidity. Temperature and Humidity recorded serially with two variable dht11_rh and dht11_temp are transferred through a single wire protocol with precise timing of every 1 hour to gather data set. Renesas microcontroller of RL78 is connected to a DHT11 sensor and GSM module (GSM Sim 900/1800 Modem), microcontroller send the start pulse to the sensor data pin by making low to high to receive response pulse from the sensor. Then gathered data set will be communicated at user end through GSM module, here communicate are done with microcontroller signals with three basic signals namely receive (RXD), transmit (TXD) and common ground (GND) to send a message to user end as shown in Figure 4. The GSM module responds to a microcontroller for the AT commands to send and receive messages from serial buffer register with GSM read or write function. Also the RFD based duty cycling based energy saving is adopted. The data sets are collected in the Mysore region for two different seasons by placing the sensor device at the farm field above ground level of 8-10 feet and the sensor is put in a plastic pipe with several pores to read accurate data. The $3 / 4^{\text {th }}$ of pipe will be dumped in the farm field soil vertically, and then the sensor connected wire is kept inside the pipe. The sensor reads the data for a regular interval of every 1 hour and transfers the data for analysis through a GSM module. Here the sensors are used to measure the soil and plant Temperature and relative humidity, so sensors are placed at the bottom of plant roots with the help of plastic pipe having pores in it. These sensors are placed at 100 plots, each 50 plots from Varuna and Pandavapura region to collect data sets for 50 days and received data from the field. The sensors are placed with a distance of 300-400 meters each to gather the datasets of fields. Figure 3 shows the dataset received to farmers. 
A total number of 35,893 datasets (for 2 seasons of 50 days, here the datasets are normalized for 6 hours i.e., per day 24 hours datasets received were normalized into 4 datasets) of temperature and humidity have been collected for both season 1 and 2 (actual datasets theoretically 2,40,000, where this are normalized to 40,000, due to technical problems we got 35,893 datasets). 17,929 datasets have been collected during season 1 (9,147 datasets from the Varuna region of Mysore and 8,782 datasets from the Pandavapura region of Mandya), 17,964 datasets were collected in season 2 (9,027 datasets from the Varuna region of Mysore and 8,937 datasets from the Pandavapura region of Mandya).

\section{EXPERIMENTATION}

In this section, we analyze the data of the experiments conducted based on the proposed method for the optimization of water usage depending on the stages of crop growth. In the first stage, validation for the gathered datasets is done for selected crops depending on the stages of growth. In the second stage, optimization of water usage is carried out depending on the relevant parameters of the conditions of the field. For the first stage, a Symbolic classifier method has been applied to validate the WSN gathered datasets to know the acceptance and non-acceptance count for each chosen crop. In the second stage, an APSim based mathematical model is designed to optimize the water usage for each crop.

This database has temperature and relative humidity from both Varuna and Pandavapura region of season 1 and 2 each. The average values of temperature and relative humidity are taken using a Statistical mean for both the Varuna and Pandavapura regions. Datasets collected for every 6 hours (normalized 6 datasets into 1dataset) from each $50 \mathrm{WSN}$ devices are averaged through the Statistical mean to know the best crops that can be grown in the entire region based on the plant growth stages

Figure 2. Architecture of wireless sensor device

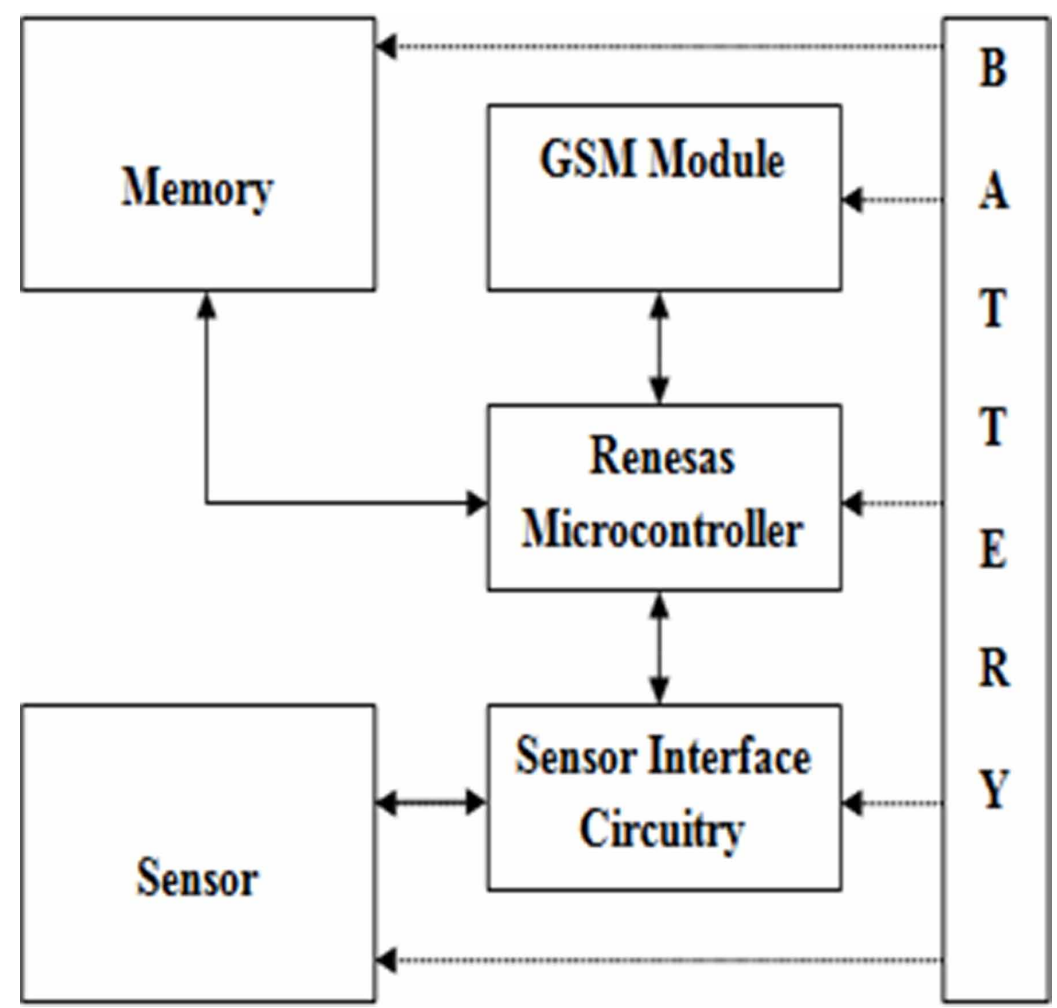


Figure 3. Data-Sets sent from Wireless Sensor Node through a GSM module to the registered cell

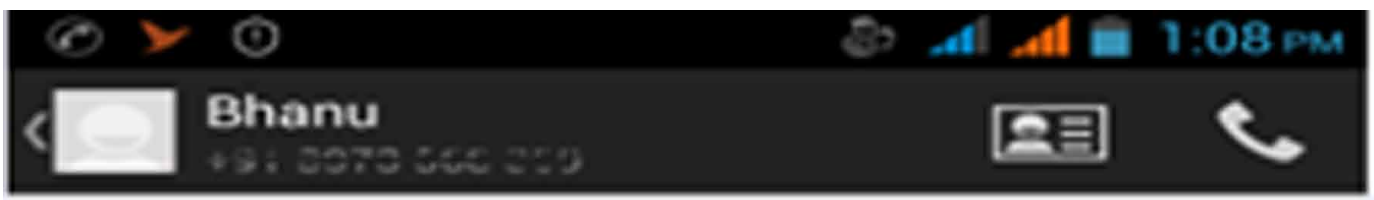

\section{@N25 Humidity $=63$ and \\ Temperature $=25$ BATSOK}

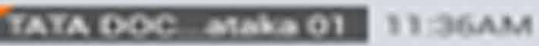

\section{$@$ N25 Humidity $=53$ and \\ Temperature $=21 \mathrm{BAT} \$ \mathrm{OK}$ \\ TAROOC AtakO $12.45 \mathrm{MM}$}

\section{@25 Humidity $=68$ and \\ Temperature $=29$ BAT $30 K$}

TATA OOO $010 \times 5012400 M$

\section{@N25 Humidity $=56$ and \\ Temperature $=27$ BAT $30 K$

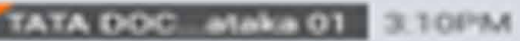

\section{@N25 Humidity $=83$ and Temperature $=27$ BATSOK TARAOCC ATAKOI $4360 \mathrm{M}$}

and varied climatic conditions. The flow chart in Figure 5 shows the working of the complete model. In the first phase, anyone specific crop from the okra, tomato, bell pepper, cucumber, and cabbage types is selected. Each crop has four stages of growth namely germination, seedling, pollination and fruit-set stages with days of varying growth (For simulation experimentation, considered the normal healthy grown plants in the regions).

For further analysis, obtained values are applied to the APSim simulator as follows. The temperature and relative humidity datasets collected from the farm field are stored in the ms excel 
Figure 4. Interfacing of DHT11 with a microcontroller. DHT11 Communication Process in response to MCU (Microcontroller)
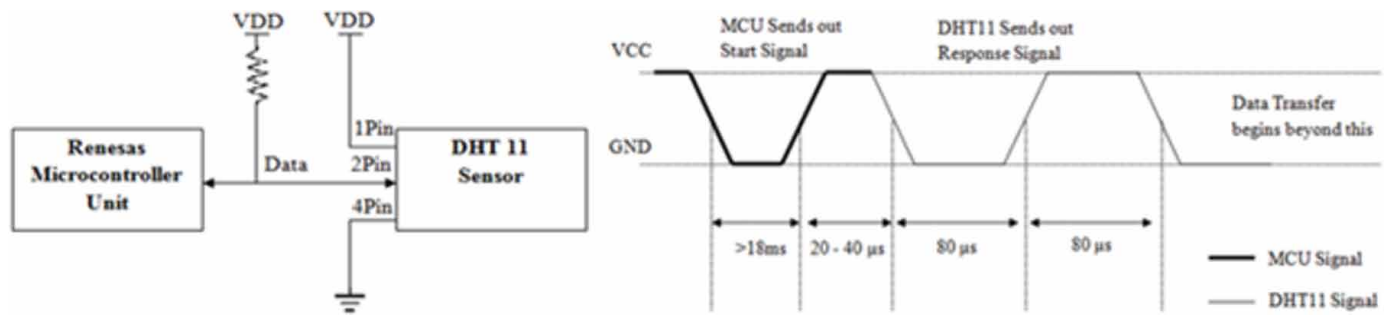

sheet with respective day and period to count the validation and non-validation for collected data-sets. Here the decision model is built to the agriculture field for supporting the farmers through the gathered datasets. In the next stage, datasets are applied to an APSim platform based mathematical model for optimizing water usage in the case of select crops (Brown, H.E et al., 2014). It is designed considering the soil evaporation factor, soil water relationship, plant available water capacity (PAWC), root zone depletion fraction, water content at field capacity, water stress coefficient, basal crop coefficient, water content at wilting point, rooting depth, total available water, readily available water and the physical characteristics of the soil such as depth and structure as shown in Figure 6.

The mathematically based computer simulation model evaluates the potential energy in both soil and water that is available for extraction to the roots of plants. In wet soil, water has high potential energy and moves freely to the plant roots. In dry soil, water has low potential energy and is strongly bound by the soil matrix and is hardly taken up by the plant roots. From Equation 4.1 we can estimate the actual crop evapotranspiration for selected crops by taking the reference evapotranspiration as $3 \mathrm{~mm} /$ day at both regions.

$\mathrm{ET}_{\mathrm{C}, \mathrm{act}}=\left[\mathrm{K}_{\mathrm{S}} * \mathrm{~K}_{\mathrm{C}}+\mathrm{K}_{\mathrm{E}}\right] * \mathrm{ET}_{\mathrm{O}}$

Where, $\mathrm{ET}_{\mathrm{C}, \mathrm{act}}=$ actual crop evapotranspiration.

$\mathrm{K}_{\mathrm{S}}=$ water stress coefficient.

$\mathrm{K}_{\mathrm{C}}=$ basal crop coefficient.

$\mathrm{K}_{\mathrm{E}}=$ soil evaporation.

$\mathrm{ET}_{\mathrm{O}}=$ reference evapotranspiration.

Table 1 shows the depletion fraction (p) for selected crops namely okra, tomato, bell pepper, cucumber, and cabbage. Here the values are taken in consultation with the experts at the "Horticulture Department in Mysore" regarding normal growth conditions for the crops. It represents a normal variation of 0.20 to 0.80 of the soil moisture levels for any of the crops grown. Table 2 shows the calculated values for selected crops based on their growth stages.

$\mathrm{TAW}=1000\left[\theta_{\mathrm{FC}}-\theta_{\mathrm{WP}}\right] * \mathrm{Z}_{\mathrm{R}}$

Where, $\theta_{\mathrm{FC}}=$ water content at field capacity.

$\theta_{\mathrm{WP}}=$ water content at wilting point.

$\mathrm{Z}_{\mathrm{R}}=$ rooting depth.

$\mathrm{RAW}=(\mathrm{p} * \mathrm{TAW})$ 


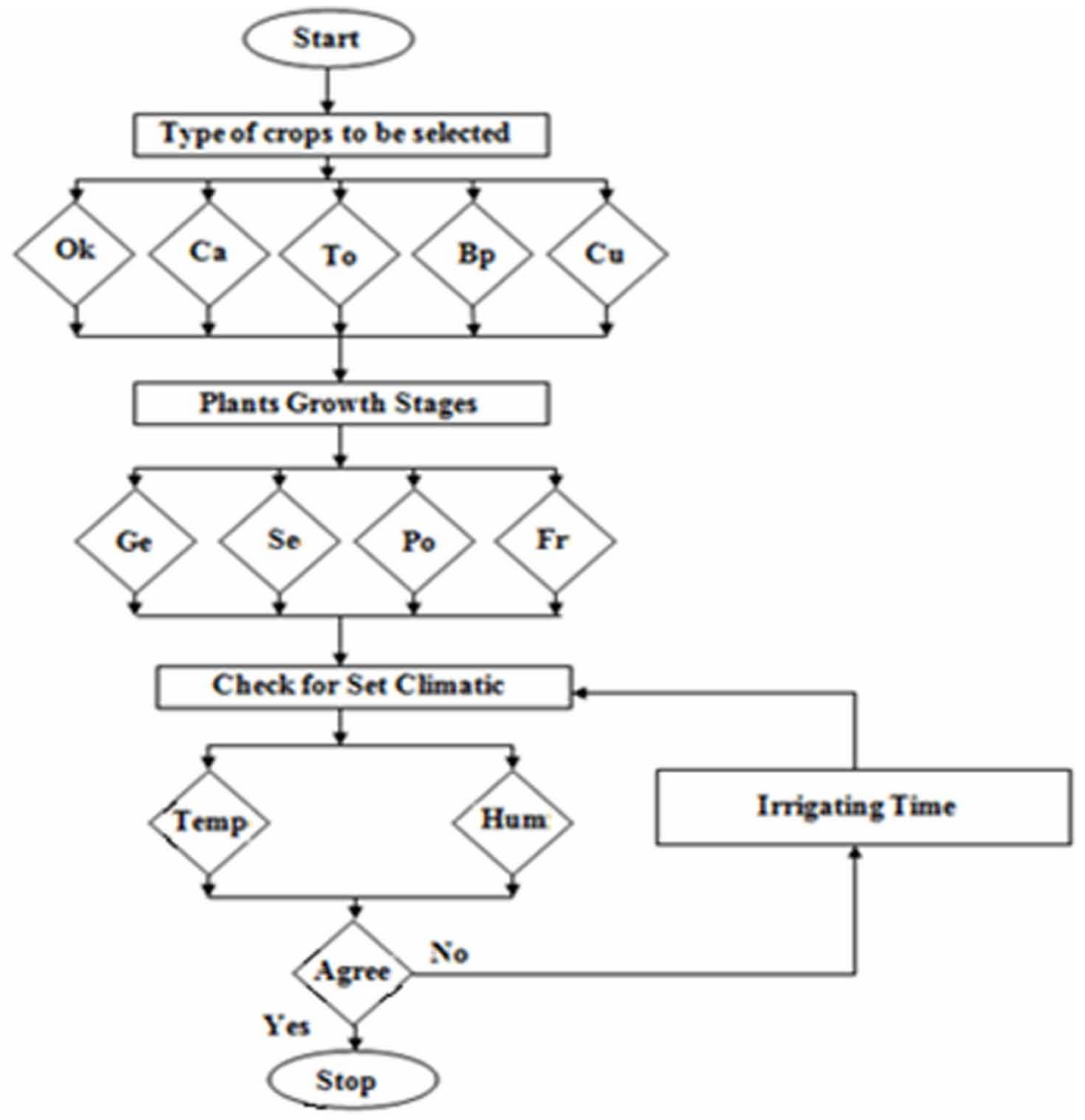

Here
Ok: Okra
$\mathrm{Ca}$ : Cabbage
To: Tomato
Bp: Bell Pepper
Cu: CucumberGe: Germination
Se: Seedling
Po: Pollination
Fr: Fruit-Set Temp: Temperature Hum: Humidity

Where, $\mathrm{p}=$ Depletion fraction.

The Total Available Water (TAW) and Readily Available Water (RAW) for the respective plants can be found using Equation 4.2 and Equation 4.3. The water content at field capacity $\left(\theta_{\mathrm{FC}}\right)$ is taken as 0.15 and water content at wilting point $\left(\theta_{\mathrm{wP}}\right)$ is taken as 0.06 based on the field observation by horticulture department consultation. The root depth $\left(\mathrm{Z}_{\mathrm{R}}\right)$ for a crop is taken with variations such as $15 \mathrm{~cm}$ (growth stage 1), $30 \mathrm{~cm}$ (growth stage 2), $30 \mathrm{~cm}$ (growth stage 3) and $45 \mathrm{~cm}$ (growth stage 4). The total amount of water that the crop can extract from the root is called TAW, where it depends on the soil texture and the rooting depth of a plant. The water uptake process in a plant root zone shows a part of water being held by soil particles in greater force. It gradually lowers the potential energy and makes it more difficult for a plant to extract it. Ultimately, when a wilting point is reached water uptakes become zero when the crop can no longer extract the remaining water. Even if the water is available until the wilting point is reached, the water uptake of the crop will be reduced. When 
Figure 6. Volumetric water analysis for selected crops using APSim

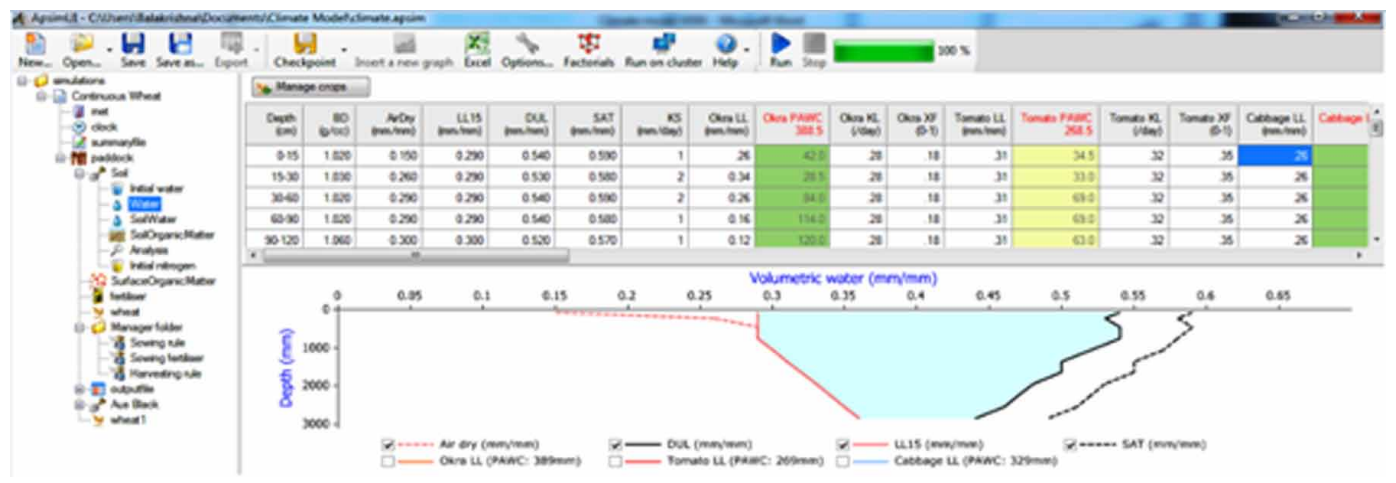

Table 1. Depletion fraction of selected crops

\begin{tabular}{|c|c|c|c|c|c|}
\hline Crop & Okra & Tomato & Cabbage & Bell pepper & Cucumber \\
\hline P & 0.45 & 0.40 & 0.45 & 0.30 & 0.50 \\
\hline
\end{tabular}

Table 2. Range of $K_{E}$ and $K_{C}$ for selected crops

\begin{tabular}{|c|c|c|c|c|c|c|}
\hline Plants Growth Stages & \multirow{2}{*}{$\mathbf{K}_{\mathbf{E}}(\mathbf{m m})$} & \multicolumn{5}{|c|}{$\mathbf{K}_{\mathbf{C}}$} \\
\cline { 3 - 7 } & & Okra & Tomato & Cabbage & Bell pepper & C u c u m b e r \\
\hline 1 & 18 & 0.50 & 0.60 & 0.55 & 0.60 & 0.60 \\
\hline 2 & 28 & 1.05 & 1.15 & 1.10 & 1.05 & 1.00 \\
\hline 3 & 28 & 1.05 & 1.15 & 1.10 & 1.05 & 1.00 \\
\hline 4 & 12 & 0.90 & 0.80 & 0.80 & 0.90 & 0.90 \\
\hline
\end{tabular}

the soil is wet, the supply of water is faster and water uptake by the crop equals the $\mathrm{ET}_{\mathrm{C}}$. When soil water content falls below the threshold values, water cannot be transported to the root zone of the crop and it experiences stress. Soil water depletion fraction is considered with the TAW for avoiding water stress for roots. The TAW and RAW for the selected crops with varying stages of growth are given in Table 3.

$$
\mathrm{K}_{\mathrm{s}}=\frac{T A W-D_{R Z}}{T A W-R A W}
$$

Where, $\mathrm{K}_{\mathrm{S}}=$ Soil water stress coefficient

$D_{R Z}=$ root zone depletion.

TAW $=$ Total available water

RAW $=$ readily available water 
Table 3. Determination of Total and readily available water for selected crops under varying growth stages

\begin{tabular}{|c|c|c|c|c|c|c|}
\hline Plants Growth Stages & & Okra & Tomato & Cabbage & Bell pepper & Cucumber \\
\hline \multirow{2}{*}{$\mathbf{1}$} & TAW & 13.5 & 13.5 & 13.5 & 13.5 & 13.5 \\
\cline { 2 - 8 } & RAW & 6.075 & 5.4 & 4.05 & 6.75 & 6.075 \\
\hline \multirow{2}{*}{$\mathbf{2} \& \mathbf{3}$} & TAW & 27 & 27 & 27 & 27 & 27 \\
\cline { 2 - 8 } & RAW & 12.15 & 10.8 & 8.10 & 13.5 & 12.15 \\
\hline \multirow{2}{*}{4} & TAW & 40.5 & 40.5 & 40.5 & 40.5 & 40.5 \\
\cline { 2 - 8 } & RAW & 18.225 & 16.2 & 12.15 & 20.25 & 18.225 \\
\hline
\end{tabular}

$\mathrm{K}_{\mathrm{S}}=1$ if $D_{R Z}<\mathrm{RAW}$

For estimation of the soil water stress coefficient, the mathematical model takes the values of TAW, RAW, $D_{R Z}$ and simulates as in Equation 4 . The $\mathrm{K}_{\mathrm{S}}$ determines the daily water requirement for the root zone of a crop. Equation 5 specifies that no water is required for the crop root zone at this stage.

\section{RESULTS}

In this section, we present the results of experiments conducted for a model based on our datasets. A computer simulation model shows the graph of TAW, RAW, Required water 1 and Required water 2 for the selected plants depending on both the environmental and field parameters keeping in mind the stages of growth based on the equations 1 to 4 . TAW represents the capacity of the soil to retain water for plants after irrigation is done for the same from the root zone. RAW represents a fraction of TAW when a plant extracts water without suffering water stress. Required water 1 represents the actual water requirement for the growth of the chosen plants, while Required water 2 represents the simulated water requirement for the chosen plants. Figure 7 shows the water required for specific crops for Season 1 at the Varuna region depending on the climate. It helps save water by giving it as required to the plants keeping in mind climatic conditions. Here the KC, KE, KS, ET, p, ZR and DRZ value are changed day by day, for the stages given in Equation $1-5$.

Table 4 shows a performance analysis of water optimization for select crops like okra, tomato, cabbage, bell pepper, and cucumber. Computer analysis has been done for the best two seasons chosen to grow five selected crops for both regions of Varuna and Pandavapura. Performance analyses have been done by taking into consideration the water requirement type 2 with water requirement type 1 , which helps decide water optimization efficiency. This result has been compared to the excessive wasting of water through compared with drip irrigation and sprinkler irrigation method carried in Indian farming and has achieved water savings as given in Table 4 (Government of Agriculture, 2013). The datasets range up to 35,893 in numbers and are about both temperature and relative humidity for two seasons. When compared to all previous work, datasets are in larger numbers, the parameters being considered are larger too in our research work.

The conceptual diagram for the information decimation is as shown in Figure 8, where information in the server is forwarded through a Way2SMS gateway protocol.

Here the integration of a way2sms with a web host server manages the automation of the information at the farmer's end. Information like the precise time of irrigation. Figure 9 shows some sample messages which have been forwarded to the farmers to indicate 
Figure 7. Water required for specific crops for Season 1 at the Varuna region

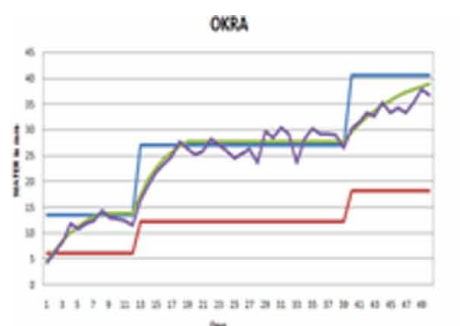

$\infty$

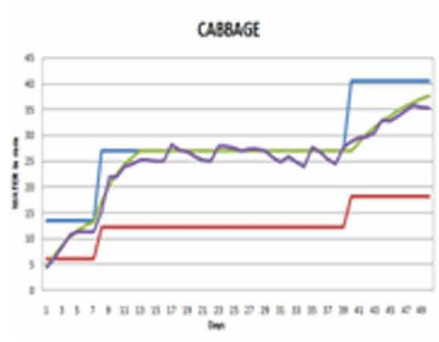

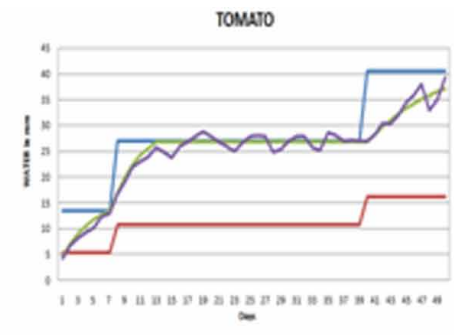

BEu

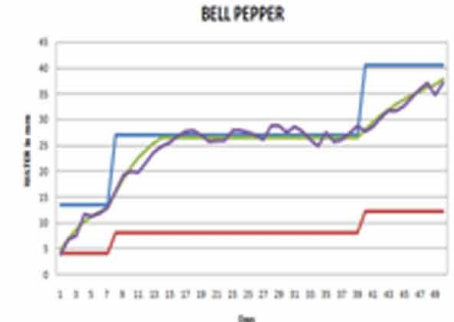

cucumers

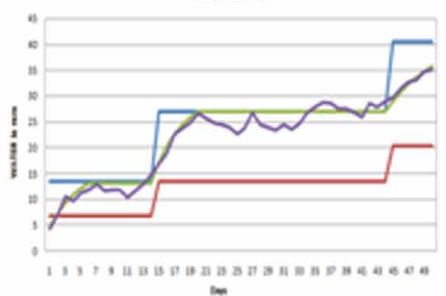

$$
\begin{aligned}
& \text { 一⿻上丨 } \\
& \text { - un } \\
& \text {-Req Wixeen! } \\
& \text {-leqWater? }
\end{aligned}
$$

Table 4. Optimization of water for selected crops

\begin{tabular}{|c|c|c|c|c|}
\hline \multirow{2}{*}{ Crops } & \multicolumn{2}{|c|}{ Water Optimization in Varuna } & \multicolumn{2}{c|}{ Water Optimization in Pandavapura } \\
\cline { 2 - 5 } & $\begin{array}{c}\text { Season 1 } \\
\text { *Water saved } \\
\%\end{array}$ & $\begin{array}{c}\text { Season 2 } \\
\text { *Water saved } \\
\%\end{array}$ & $\begin{array}{c}\text { Season 1 } \\
\text { *Water saved } \\
\%\end{array}$ & $\begin{array}{c}\text { Season 2 } \\
\text { *Water saved \% }\end{array}$ \\
\hline Okra & 52.56 & 54.27 & 51.05 & 56.23 \\
\hline Tomato & 59.57 & 64.40 & 58.53 & 57.27 \\
\hline Cabbage & 60.52 & 62.84 & 59.14 & 60.84 \\
\hline Bell Pepper & 53.68 & 58.37 & 57.45 & 57.29 \\
\hline Cucumber & 50.45 & 57.59 & 50.28 & 54.64 \\
\hline
\end{tabular}

*Water Saved with reference (Government of Agriculture, 2013), 70\% of the excess water has been used every year.

\section{CONCLUSION}

In this research work, a WSN real-time based climatic model has been developed for selected crops like okra, tomato, bell pepper, cucumber and cabbage which were shown to optimize the water usage. Water optimization achieved in both regions for the chosen crops has been with variations ranging from $80.28-92.48 \%$ with water savings range from $50.28-64.40 \%$. With the advent of modern technologies to optimize the irrigation, there exist a lot of scope innovative and efficient systems. To further improvisation for irrigation optimization, we also suggest considering real growth stages of plants in the farm fields instead of standard datasets. This will help to scenarios most relevant to policies and decision makers. 


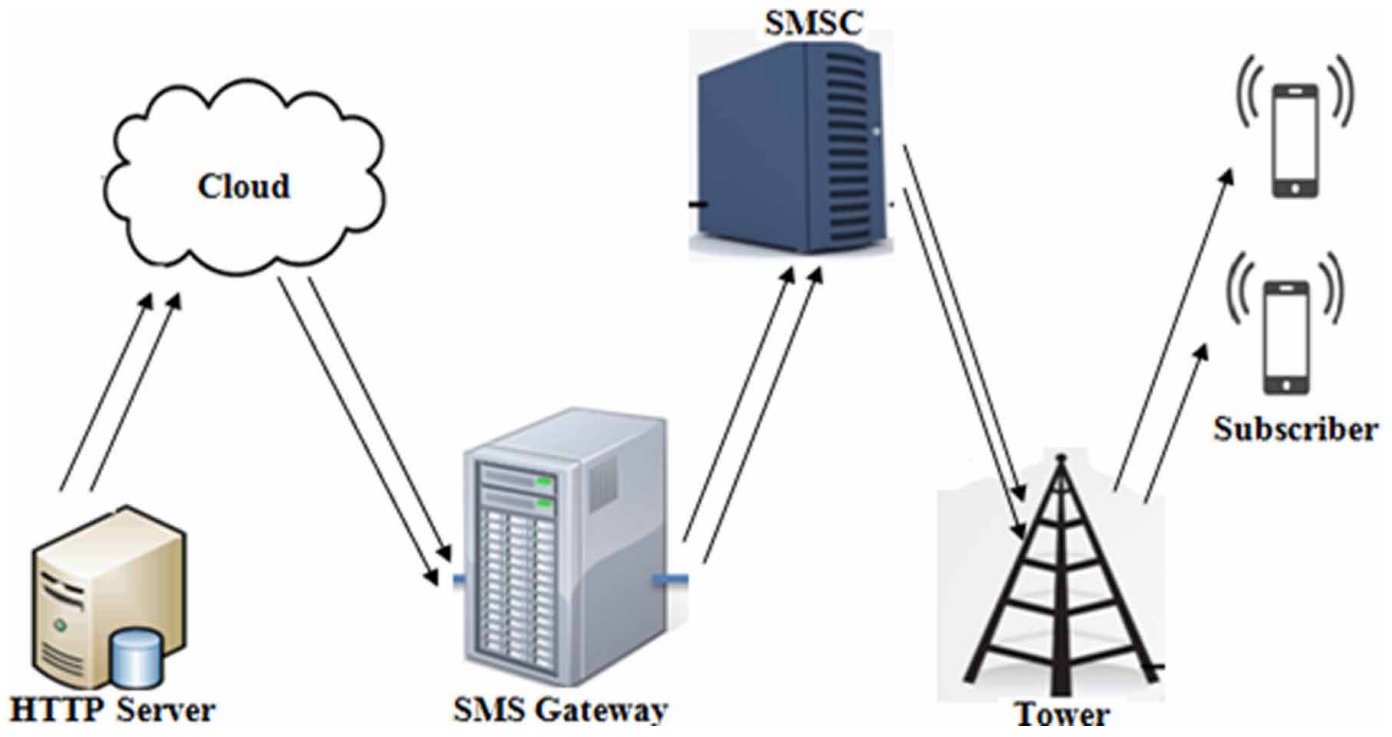

Figure 9. Information dissemination to the farmers for irrigation time

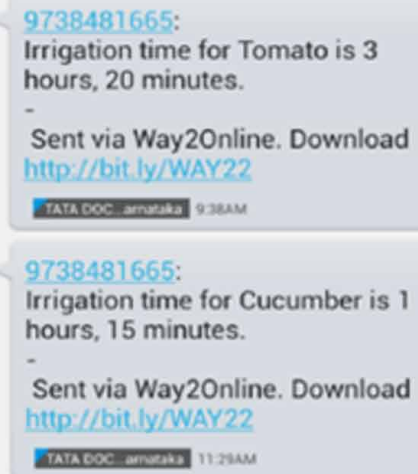

Sent via Way2Online. Download http///bit ly/WAY22

\section{5:}

Irrigation time for Cucumber is 1 hours, 15 minutes.

Sent via Way2Online. Download http ///bit.ly/WAY22

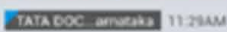

9738481665:

Irrigation time for Bell Pepper is 1 hours, 35 minutes.

Sent via Way2Online. Download http://bit.ly/WAY22

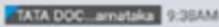

\section{5:}

Irrigation time for Cabbage is 1 hours, 45 minutes.

Sent via Way2Online. Download http://bit.ly/WAY22

axpoce monsm 11 xous
9738481665 :

Irrigation time for Okra is 2 hours, 40 minutes.

Sent via Way2Online. Download http://bit.ly/WAY22

\section{axpooc moned nases}

\section{5:}

Irrigation time for Tomato is 2 hours, 30 minutes.

Sent via Way2Online. Download hittp://bit.ly/WAY22

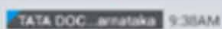




\section{REFERENCES}

Anisi, M. H., Abdul-Salaam, G., \& Abdullah, A. H. (2015). A survey of wireless sensor network approaches and their energy consumption for monitoring farm fields in precision agriculture. Precision Agriculture, 16(2), 216-238. doi:10.1007/s11119-014-9371-8

Balakrishna, K., \& Rao, M. (2019). Tomato Plant Leaves Disease Classification Using KNN and PNN. International Journal of Computer Vision and Image Processing, 9(1), 51-63. doi:10.4018/IJCVIP.2019010104

Brown, H. E., Huth, N. I., Holzworth, D. P., Teixeira, E. I., Zyskowski, R. F., Hargreaves, J. N. G., \& Moot, D. J. (2014). Plant Modelling Framework: Software for building and running crop models on the APSIM platform. Environmental Modelling \& Software, 62, 385-398. doi:10.1016/j.envsoft.2014.09.005

Chartzoulakis, K., \& Bertaki, M. (2015). Sustainable water management in agriculture under climate change. Agriculture and Agricultural Science Procedia, 4, 88-98. doi:10.1016/j.aaspro.2015.03.011

Culibrina, F. B., \& Dadios, E. P. (2015). Smart farm using wireless sensor network for data acquisition and power control distribution. 2015 International Conference on Humanoid, Nanotechnology, Information Technology, Communication and Control, Environment and Management (HNICEM), 1-6. doi:10.1109/ HNICEM.2015.7393215

D-Robotics UK. (2010). DHT11 Humidity and Temperature Sensor, micropik 2010. Author.

Diedrichs, A. L., Tabacchi, G., Grünwaldt, G., Pecchia, M., Mercado, G., \& Antivilo, F. G. (2014). Low-power wireless sensor network for frost monitoring in agriculture research. 2014 IEEE Biennial Congress of Argentina (ARGENCON), 525-530. doi:10.1109/ARGENCON.2014.6868546

Government of Agriculture. (2013). State of Indian Agriculture 2012-13. Ministry of Agriculture Department of Agriculture \& Cooperation New Delhi.

Jensen, M. E., \& Allen, R. G. (2016). Evaporation, Evapotranspiration, and Irrigation Water Requirements (2nd ed.). ASCE Manuals and Reports on Engineering Practice No. 70. American Society of Civil Engineers.

Jin, N., Ma, R., Yunfeng, Lv., Lou, X., \& Wei, Q. (2010). A novel design of water environment monitoring system based on WSN. 2010 International Conference On Computer Design and Applications, V2-593-V2-597.

Kaewmard, N., \& Saiyod, S. (2014). Sensor data collection and irrigation control on vegetable crop using smart phone and wireless sensor networks for smart farm. 2014 IEEE Conference on Wireless Sensors (ICWiSE), 106112. doi:10.1109/ICWISE.2014.7042670

Khriji, S., Houssaini, D. E., Jmal, M. W., Viehweger, C., Abid, M., \& Kanoun, O. (2014). Precision irrigation based on wireless sensor network. Science Measurement \& Technology IET, 8(3), 98-106. doi:10.1049/ietsmt.2013.0137

Kodali, Rawat, \& Boppana. (2014). WSN sensors for precision agriculture. 2014 IEEE Region 10 Symposium, 651-656.

Le \& Tan. (2015). Design and Deploy a Wireless Sensor Network for Precision Agriculture. 2015 2nd National Foundation for Science and Technology Development Conference on Information and Computer Science (NICS).

Mat, I., Kassim, M. R. M., \& Harun, A. N. (2014). Precision irrigation performance measurement using wireless sensor network. 2014 Sixth International Conference on Ubiquitous and Future Networks (ICUFN), 154-157. doi:10.1109/ICUFN.2014.6876771

Mohd Kassim, M. R., Mat, I., \& Harun, A. N. (2014). Wireless Sensor Network in precision agriculture application. 2014 International Conference on Computer, Information and Telecommunication Systems (CITS), 1-5. doi:10.1109/CITS.2014.6878963

Nandurkar, S. R., Thool, V. R., \& Thool, R. C. (2014). Design and development of precision agriculture system using wireless sensor network. 2014 First International Conference on Automation, Control, Energy and Systems (ACES), 1-6. doi:10.1109/ACES.2014.6808017

Navarro-Hellín, H., Martínez-del-Rincon, J., Domingo-Miguel, R., Soto-Valles, F., \& Torres-Sánchez, R. (2016). A decision support system for managing irrigation in agriculture. Computers and Electronics in Agriculture, 124, 121-131. doi:10.1016/j.compag.2016.04.003 
Navarro-Hellín, H., Torres-Sánchez, R., Soto-Valles, F., Albaladejo-Pérez, C., López-Riquelme, J. A., \& Domingo-Miguel, R. (2015). A wireless sensors architecture for efficient irrigation water management. Agr. Water Management, 151, 64-74. doi:10.1016/j.agwat.2014.10.022

Ojha, T., Misra, S., \& Raghuwanshi, N. S. (2015). Wireless sensor networks for agriculture: The state-of-theart in practice and future challenges. Computers and Electronics in Agriculture, 118(3), 66-84. doi:10.1016/j. compag.2015.08.011

Research Design Lab. (1800). GSM Sim 900. Modem.

Rinaldi, M., \& He, Z. (2014). Decision support systems to manage irrigation in agriculture. Advances in Agronomy, 123, 229-279. doi:10.1016/B978-0-12-420225-2.00006-6

Srbinovska, M., Gavrovski, C., Dimcev, V., Krkoleva, A., \& Borozan, V. (2015). Environmental parameters monitoring in precision agriculture using wireless sensor networks. Journal of Cleaner Production, 88, $297-307$. doi:10.1016/j.jclepro.2014.04.036 